\title{
A contribuição do bibliotecário para a educação ambiental
}

\author{
Nathalice Bezerra Cardoso
}

\author{
Graduada em Biblioteconomia pela Universidade \\ Federal do Estado do Rio de Janeiro - UNIRIO. \\ Bibliotecária do Fundo Brasileiro para \\ Biodiversidade - Funbio
}

Discute a contribuição do bibliotecário para a Educação Ambiental, mostrando a importância dele como educador, levando conhecimento teórico e ações práticas para as pessoas, com $o$ intuito de que tenham hábitos ecologicamente corretos. Apresenta o perfil do bibliotecário considerando-o como o profissional que dissemina a informação, acreditando que ele não pode ficar de fora dessas discussões; também estes enquanto cidadãos e profissionais devem atuar nessa área, ajudando da melhor forma possível a disseminar a informação ambiental, criando estratégias, redes, projetos e outras ações para conscientizar as pessoas e diminuir o impacto do ser humano no meio ambiente. Ressalta que a área de Biblioteconomia tem e deve se relacionar com a Educação Ambiental. Assim, o bibliotecário estará contribuindo para gerar pensamentos críticos, alcançar comportamentos ecologicamente corretos, além de contribuir para o desenvolvimento sustentável da região.

Palavras- chave: Biblioteconomia; Educador; Educação Ambiental; Informação Ambiental; Meio Ambiente.

\section{Librarian's contribution for environmental education}

The article discusses the contribution of the librarian for Environmental Education, pointing out his/her importance as an educator while bringing not only theoretical knowledge but also influencing actions for people so they develop ecologically correct habits. As the librarian is considered one of the professionals who disseminate information, it is believed that he/she cannot stay out of these discussions. Librarians as citizens and professionals must also act in this area, working at his/her best to 
disseminate environmental information, create strategies, networks, projects and other actions to keep people aware of the problems and reduce the impact of humans on the environment. This research also shows that librarianship should and must relate to environmental education. This way, his/her work would help to generate critical thinking, acquire environmentally correct behaviors, and contribute to a sustainable development in the region.

Keywords: Librarianship; Educator; Environmental Education; Environmental information; Environment.

Recebido em 01.06.2010 Aceito em 30.06.2010

\section{Introdução}

Atualmente, existe grande preocupação com 0 futuro da humanidade em relação às questões ambientais. Mudanças climáticas, poluição e recursos naturais estão sendo cada vez mais citados e discutidos. Como o bibliotecário é considerado um dos profissionais que dissemina a informação, acredita-se que ele não pode ficar de fora dessas discussões.

Partindo desse contexto, o presente trabalho visa relacionar o trabalho do bibliotecário com o meio ambiente, mostrando que a Biblioteconomia é uma área de conhecimento que deve interligar-se à Educação Ambiental, por conseguinte, o profissional/bibliotecário estará contribuindo para gerar pensamentos críticos, alcançar comportamentos ecologicamente corretos, além de contribuir para o desenvolvimento sustentável da região, onde particularmente atua.

A educação tradicional, aquela que aprendemos dentro dos muros das escolas e das universidades, tem um papel fundamental para 0 desenvolvimento de um sujeito consciente na sociedade. Quando o assunto vai ao encontro de questões ambientais, percebe-se que a consciência ambiental é de grande importância e, no entanto, nem sempre é despertada nas escolas. Logo, surge a reflexão: de que adianta adquirirmos conhecimento se não respeitamos a natureza, se esquecemos que o homem é parte integrante dela, que tudo à sua volta compõe-se de recursos naturais e que sem eles não existiria vida.

Nesse sentido, acredita-se que os bibliotecários como cidadãos e profissionais também devem atuar nessa área, ajudando da melhor forma possível a disseminar a informação ambiental, criando estratégias, redes, projetos e outras ações para conscientizar as pessoas e diminuir o impacto do ser humano no meio ambiente. É interessante também que o ensino de Biblioteconomia seja atualizado, levando-se em consideração as mudanças globais. De acordo com esta linha de pensamento, a grade curricular dos cursos poderia ir além das atividades técnicas como a 
catalogação, a classificação, a indexação, entre outras. É preciso que o bibliotecário se preocupe também com o meio ambiente, com a qualidade de vida e o desenvolvimento da região que atua.

Acredita-se que os bibliotecários que atuam em bibliotecas escolares e públicas são os que possuem um maior potencial para trabalhar com a Educação Ambiental, pois convivem com crianças e jovens que serão os futuros responsáveis pela preservação do meio ambiente e os difusores dessas ações e informações, melhorando, assim, o "status" ambiental da região.

Dentro desse contexto, esta pesquisa tem por objetivo discutir a contribuição do bibliotecário para a Educação Ambiental, mostrando a sua importância como educador, levando conhecimento teórico e ações práticas para as pessoas, com o intuito de que tenham ações ecologicamente corretas. Portanto, a pesquisa propõe-se a identificar as ações que estão sendo desenvolvidas na área de Biblioteconomia relacionadas à Educação Ambiental, apontando trabalhos e projetos que possam incentivar o despertar da conscientização ambiental. Sabe-se da existência de bibliotecas que promovem projetos de Educação Ambiental e trabalham essas ações. É importante identificá-las para analisar a pertinência dessas idéias, comparando a teoria com a prática. Ainda para alcançar esses objetivos, considera-se necessário discutir o perfil do Bibliotecário, levando-se em consideração suas atividades de trabalho e as habilidades necessárias para que este profissional atue como educador.

Cabe esclarecer que a escolha do tema justifica-se, em primeiro lugar, pela experiência de trabalho da autora no Centro de Documentação da ONG Fundo Brasileiro para a Biodiversidade (Funbio). Essa experiência proporcionou, além do próprio processo de despertar da consciência ambiental, o interesse em difundí-la. Em segundo lugar, por ser uma das idealizadoras do projeto voluntário "Trilhas de histórias", o qual, além de ter como objetivo principal o incentivo à leitura, visa também conscientizar os alunos da Instituição Solar Meninos de Luz à prática de ações ecologicamente corretas. Nele, há a intenção de unir leitura e conscientização ambiental de forma produtiva, de maneira que as duas áreas de conhecimento - Biblioteconomia e Educação ambiental - sejam trabalhadas de forma multidisciplinar.

Em relação à metodologia para subsidiar o referencial teórico, foi feito um levantamento bibliográfico nos principais periódicos da área de Biblioteconomia dentro do portal Capes. Os termos usados na busca foram: biblioteconomia, meio ambiente e educação ambiental. Constatouse que não foi encontrado nenhum artigo que contemplasse o assunto, por isso recorreu-se à biblioteca eletrônica "Scientific Electronic Library Online" (Scielo), ao Sistema de Documentação da UFRJ (Base Minerva) e ao site Google Acadêmico.

Por meio dessas ferramentas, foram recuperados os seguintes artigos que tratam do assunto: "Projeto: 'Lixo por livro'", "Trilhas de histórias: trabalhando leitura e meio ambiente nas florestas do Rio de Janeiro" e "O bibliotecário como Agente Socializador na Disseminação da Informação sobre o Meio Ambiente: relato de experiência". 
A partir desta revisão bibliográfica foi possível determinar o "estado da arte" do tema, ou seja, saber o que já existe publicado na literatura sobre o assunto, quais as lacunas existentes e onde se encontram os principais entraves. Só assim é possível comparar a teoria com a prática.

É importante esclarecer que a natureza desta pesquisa é aplicada, ou seja, tem como objetivo gerar conhecimentos que serão aplicados na prática. Esses conhecimentos irão resolver problemas específicos. Do ponto de vista da forma de abordagem do problema, a pesquisa é qualitativa, pois não pode ser traduzida em números, ou seja, esse tipo de pesquisa não requer o uso de métodos e técnicas estatísticas.

Mediante ao curto tempo para conclusão da pesquisa, optouse por não utilizar a técnica de entrevista, que contataria com os responsáveis pelos projetos de Biblioteconomia na área ambiental, identificados na literatura. Portanto, com o intuito de ampliar os conhecimentos sobre o campo pesquisado foi feita a análise dessa literatura.

\section{0 perfil do bibliotecário}

É comum que a sociedade como um todo relacione a imagem do bibliotecário com a imagem negativa de uma pessoa idosa, que geralmente usa óculos, de pouca receptividade e que fica sentada pedindo silêncio na biblioteca. De acordo com Walter e Baptista (2007, p. 30):

É muito interessante como o aspecto visual e comportamental dos bibliotecários realmente permeia o imaginário popular, associando a profissão a mulheres, em geral idosa [...] com dois adereços principais, [...] que são os indefectíveis óculos e - famigerado coque nos cabelos, além de uma postura geralmente antagônica e pouco receptiva para os usuários, provavelmente em gesto que indique um enfático pedido de silêncio.

O papel do bibliotecário é normalmente associado ao de um mero "guardador de livros". Isso se deve ao fato de que por muito tempo seu objeto de trabalho e estudo estivesse focado no livro. Dessa forma, sua atuação era restrita aos limites físicos de uma biblioteca e de seu acervo. Theodoro Ezequiel da Silva (1999, p. 103) afirma que esses profissionais:

[...] parecem exercer um papel passivo, de mero entregador de livros, colocando-se fora dos circuitos de interlocução e de interação [...]. Talvez resida ai o "pêndulo manco" da biblioteconomia brasileira: o trabalho cotidiano e prático tende para a área técnica, mas é incapaz de transformar em ação concreta o discurso [...] em torno da necessidade de reflexão sobre o social. 
O bibliotecário, por muitos anos, dedicou-se às atividades mecanizadas e técnicas, o que contribuiu muito para formar essa imagem de um profissional preso ao espaço de uma biblioteca e que "não sai de trás do balcão". O rompimento do bibliotecário com esse tecnicismo alienante é defendido por Moraes (1983, p. 22):

A preocupação técnica exclusiva é tão prejudicial quanto a sua inexistência. O bibliotecário moderno deve ser um misto de técnico e intelectual. A sua preocupação principal não deve ser datilografar fichas perfeitas, segundo código de catalogação, mas reconhecer o conteúdo dos livros que possui, ser um guia intelectual do leitor. Muitos bibliotecários esquecem que a principal coisa, na biblioteca, para o leitor, é o livro e não a técnica que se empregou para catalogá-lo e classificá-lo.

Ainda hoje existem profissionais que se preocupam exclusivamente com a técnica e não conseguem perceber que com isso estão contribuindo para preservar o estereótipo do bibliotecário guardião de livros, dono de bibliotecas, de postura muitas vezes arrogante e que cria barreiras ao acesso à informação. Nessa linha de pensamento são esclarecedoras as palavras de Theodoro Ezequiel da Silva (1999, p. 99):

O problema da biblioteconomia brasileira está na mentalidade retrógrada de um grande número de bibliotecários, que se apresentam como pequenas autoridades: donas dos espaços públicos; reprodutoras cegas de normas esclerosadas; escravas das fichas de catalogação e de sistemas fechados de consulta; seguidoras servis dos códigos (e não dos caminhos concretos da vida); zumbis de espaços compartimentalizados; marionetes alienadas que só funcionam ao toque da burocracia, incapazes de sair dos enferrujados trilhos do tecnicismo; débeis vivendo atrás das barreiras dos balcões; seres desacostumados ao diálogo; cópias carbono dos totens autoritários e tocadores da mesmice, cujo único desafio na vida é saber quando vai sair a aposentadoria para que continuem a fazer nada do nada que sempre fizeram.

Atualmente essa imagem está sendo mudada, principalmente com a introdução de novas tecnologias de informação e da internet, rede mundial de computadores, que através da World Wide Web (www) disponibiliza uma grande quantidade de informações e alternativas para que o bibliotecário possa aumentar a qualidade e a capacidade dos serviços prestados pelas bibliotecas e/ou Centros de Informações.

Estas tecnologias estão gerando novas e diferentes demandas que até então não existiam. A Internet contribuiu também para ampliar o mercado de trabalho desse profissional e romper essa imagem restrita aos limites físicos de uma biblioteca e de seu acervo. Com o desenvolvimento 
científico e tecnológico houve uma mudança na base da sociedade. Atualmente, vive-se a chamada era da informação e do conhecimento. De acordo com Almeida Junior (2000, p. 32), o bibliotecário não ficou alheio:

[...] às transformações sociais e, para acompanhar tais transformações, foi obrigado a se modificar, a se adequar às necessidades informacionais da sociedade. [...] As reivindicações da população, em especial a de acesso à educação, exigem uma mudança da biblioteca e, por sua vez, do perfil dos que nela atuam.

O bibliotecário precisou buscar um novo papel para ser eficiente e eficaz em seu trabalho com a informação e sua disseminação. Foi preciso aceitar a internet como ferramenta de trabalho e assumir uma nova postura diante das novas tecnologias, buscando se atualizar para dominar os sistemas e as novas mídias de acesso aos principais bancos, na rede mundial de computadores.

Para entender esse processo de mudança é preciso falar sobre as competências e as habilidades desse profissional. Segundo Carvalho (1998), o profissional da informação desenvolve as seguintes atividades: administrativa; formação e manutenção do acervo; preparo técnico do acervo e a atividade de referência, que segundo ele, é o mais importante no trabalho do bibliotecário. Neste contexto, Almeida Junior (2000, p. 36) afirma que:

Entre as atribuições do bibliotecário está, até hoje, a formação do acervo e, dentro desta, a determinação do que deve ou não fazer parte do universo disponível para leitura e de informações acessíveis para uma determinada comunidade. A globalização e as tecnologias da informação disponíveis hoje quebram a idéia de um acervo restrito a quatro paredes, mas, mesmo assim, não diminuem a responsabilidade do bibliotecário na relação fontes e necessidade de informação.

De acordo com Becker (2008, p. 41), a Lei no. 4.084, de 30 de junho de 1962, cita as atribuições dos Bacharéis de Biblioteconomia. São elas:

[...] a organização, direção e execução dos serviços técnicos de repartições públicas federais, estaduais, municipais e autárquicas e empresas particulares concernentes às matérias e atividades seguintes: 0 ensino de Biblioteconomia; a fiscalização de estabelecimentos de ensino de Biblioteconomia reconhecidos, equiparados ou em via de equiparação; administração e direção de bibliotecas; a organização e direção dos serviços de documentação; a execução dos serviços de classificação e catalogação de manuscritos 
e de livros raros e preciosos, de mapotecas, de publicações oficiais seriadas, de bibliografia e referência.

Conforme a lei citada, essas seriam as atribuições desse profissional, mas de 1962 aos dias atuais, muita coisa mudou, sendo necessário realizar outras atividades, além dessas, para atender às necessidades informacionais da sociedade.

Seguindo esta linha de pensamento, Dudziak, Gabriel e Villela (2000) dizem que o bibliotecário deve ser um "agente multiplicador de idéias". Nessa direção Martucci $(1983$, p. 3) acredita que os bibliotecários devem ser agentes de transformação cultural, pois, além dos conhecimentos técnicos da sua área, devem ter conhecimentos da realidade social, política e educacional, proporcionando uma atuação comprometida na área em que atua.

É preciso que o bibliotecário se preocupe também com o meio ambiente, com a qualidade de vida e o desenvolvimento da região em que atua. Para isso, ele precisa interagir mais com os usuários e conhecer a realidade social do local. Só assim será possível descobrir quais são as suas reais demandas. Nesse sentido, o bibliotecário deve recorrer à informação utilitária para atender estas demandas. Luiz Milanesi é um dos autores que defendem essa estratégia. O trabalho focado na "informação utilitária", que, segundo Milanesi (2002), é a "forma de atender aos interesses locais", é fundamental para tornar a biblioteca um local interessante, além de mostrar a preocupação com o desenvolvimento da região. Por mais importante que seja o acervo disponível, muitas vezes ele não é de interesse para o cidadão, ao privilegiar as campanhas de vacinação, notícias sobre doenças contagiosas ou sobre as vagas de emprego abertas. O cidadão não tem interesse em pegar um livro emprestado ou tirar uma dúvida junto à biblioteca da sua localidade.

A informação utilitária vai ajudar o cidadão a solucionar problemas comuns e questões práticas do seu cotidiano. Portanto, segundo essa perspectiva, a biblioteca também deveria ser uma central informativa de interesse público, ou seja, o bibliotecário deve ficar atento ao que está acontecendo no país e disseminar os acontecimentos que são importantes para a sociedade, lembrando que a informação é um agente de transformação social. Nessa linha de pensamento, Milanesi (2002, p.107) afirma que:

[...] os profissionais da informação, necessariamente, não produzem textos, mas sabe como organizá-los. [...] têm pela frente as ferramentas da informática para organizar muito mais informações [...]. Nesse sentido, o profissional da informação, além de dispor de todo o volume informacional da internet, disseminando-o ao seu público, ainda pode incluir no conteúdo o específico local, a dita 'informação utilitária'. 
O bibliotecário também precisa manter-se atualizado e, consequentemente, conhecer as tecnologias disponíveis para atender às grandes demandas informacionais da sociedade. No entanto, em pleno século XXI, aparentemente esse profissional ainda encontra dificuldades de se adaptar às mudanças. Por isso, Sales (2004, p. 41) ressalta a necessidade de o bibliotecário buscar novas formas de atuação:

[...] humanizando mais seu trabalho - que possui caráter tecnicista - não apenas garantindo aos sujeitos o direito à informação, mas também incorporando à sua identidade profissional esta necessidade de mudança. Uma profissão meramente tecnicista está fadada à extinção. [...] Somente oferecer a informação sobre documentos e seus conteúdos, já não basta. E necessária a certeza de que ela alcançará seu destino: o entendimento de quem a busca.

\subsection{O bibliotecário como educador}

O bibliotecário pode ser considerado um educador? Para responder esta questão, será necessário tomar por base autores que vêm desenvolvendo estudos sobre esse assunto, tais como: Sales (2004), Theodoro Ezequiel da Silva (1999), Salgado e Becker (1998), Pirela e Ocando (2003), Lourenço Filho (1944), Corrêa et al. (2002) e Waldeck Carneiro Silva (1999).

Nessa direção, Sales (2004) afirma que da mesma maneira que a biblioteca escolar dificilmente é considerada como um espaço pedagógico, o bibliotecário escolar raramente é considerado e se considera um educador: "Geralmente Ihe são atribuídas funções técnicas e até burocráticas que o distancia do fazer pedagógico e da aceitação como bibliotecário escolar". Waldeck Carneiro da Silva (1999, p. 79) completa esse pensamento afirmando que:

[...] ao bibliotecário escolar, visto como educador, cabe dedicar-se menos às atividades mecanizadas e muito mais a programas de incentivo à leitura, junto aos alunos, com o apoio dos outros educadores da escola, como professores e especialistas. [...] a tarefa de orientar o aluno na utilização da biblioteca e, principalmente, o de despertar nele o gosto e o hábito da leitura são as atribuições mais reveladoras da natureza educativa do trabalho biblioteconômico na escola.

Como dito anteriormente, torna-se claro que o bibliotecário deve se desprender das atividades técnicas, sem abandoná-las, visto que tais tarefas são fundamentais em qualquer biblioteca. Imaginar uma biblioteca sem a catalogação e a classificação, por exemplo, seria impossível, pois ninguém conseguiria recuperar a informação desejada.

Os especialistas de bibliotecas escolares e públicas são os que possuem um maior potencial para atuarem como educadores, pois estão 
em contato direto com crianças e jovens que serão futuros agentes multiplicadores das ideias e dos ideais que eles possam vir a assimilar durante o aprendizado. De acordo com essa perspectiva, Becker e Salgado (1998, p. 5) afirmam que "o bibliotecário escolar tem dentre suas funções primordiais a de educar".

Para Sales (2004), a educação é um elemento capaz de garantir desenvolvimento cognitivo e discernimentos suficientes no convívio social, principalmente, neste público. Seguindo essa linha de pensamento, Pirela e Ocando (2003, p. 7) acreditam que as bibliotecas escolares permitem ao sujeito "modificar suas estruturas mentais para resolver problemas não só no âmbito acadêmico, mas também no cotidiano". Nesse sentido, são válidas as palavras de Lourenço Filho (1944, p. 3-4):

Ensino e biblioteca são instrumentos complementares [...]; ensino e biblioteca não se excluem, complementam-se. Uma escola sem biblioteca é um instrumento imperfeito. A biblioteca sem ensino, ou seja, sem alternativa de estimular, coordenar e organizar a leitura, será, por seu lado, instrumento vago e incerto.

A leitura é de grande importância para o desenvolvimento intelectual de qualquer cidadão, tornando-o crítico e participativo no meio em que vive. Nesta direção, o bibliotecário precisa trabalhar com a mediação de leitura, procurando desenvolver o gosto e o hábito de ler em seus usuários. É importante também orientá-los no contato com a biblioteca para que eles se tornem independentes em sua pesquisa, pois a motivação e o estímulo à pesquisa e ao questionamento são deveres do bibliotecário. A esse propósito, é esclarecedora a análise de Corrêa et al. (2002, p. 121):

[...] o bibliotecário desempenha algumas funções educativas [...] sua função educativa concentra-se no sentido de auxiliar a comunidade escolar na utilização correta das fontes de informação, dando um embasamento para que o educando saiba usufruir esses conhecimentos, também fora do ambiente escolar. Ele ensina a socialização, através do compartilhamento de informações, de utilização de materiais e ambientes coletivos, preparando assim 0 educando no desenvolvimento social e cultural.

Além dessas funções educativas é importante também que o bibliotecário interaja mais com outros educadores. Para apoiar efetivamente o trabalho do professor, o bibliotecário precisa participar da construção dos planos de trabalho, dos projetos e dos currículos escolares. De acordo com Waldeck Carneiro da Silva (1999, p. 77):

[...] a participação do bibliotecário escolar no planejamento didático do professor é outra atribuição de cunho educativo 
[...]. Ciente do planejamento do professor, o bibliotecário escolar conhecerá os conteúdos que serão explorados e, assim, poderá orientar com maior objetividade e eficácia a inserção da biblioteca no ensino/aprendizagem. [...] 0 bibliotecário poderá apresentar ao professor as possibilidades informativas da biblioteca escolar com relação à disciplina que irá lecionar.

Em relação às novas tecnologias, podemos dizer que o bibliotecário deve ser mediador no processo de inclusão digital. Seguindo essa linha de pensamento, Estabel e Moro (2006, p. 5) comentam que o "bibliotecárioeducador deve encantar os alunos propiciando o diálogo, a interação, a criatividade, o compartilhamento. O ambiente digital deve ser agradável, prazeroso, possibilitando que o aluno sinta-se capaz de produzir, de criar, de construir".

Com base no exposto acima, fica evidente o caráter educativo do bibliotecário. No entanto, suas funções educativas não são estimuladas em sua formação, visto que os currículos das Escolas de Biblioteconomia não contemplam disciplinas sobre o tema.

Analisando especificamente o caso do Rio de Janeiro, existem quatro faculdades que oferecem o curso de graduação em Biblioteconomia. São elas: Universidade Federal do Estado do Rio de Janeiro (UFRJ), Universidade Federal do Estado do Rio de Janeiro (UNIRIO), Universidade Federal Fluminense (UFF) e a Universidade Santa Úrsula, que é a única particular. Verificando a grade curricular dessas faculdades, percebe-se que nenhuma delas oferece disciplinas obrigatórias relacionadas à educação, à leitura e à formação de leitores. Cabe esclarecer que algumas oferecem disciplinas optativas sobre o assunto. A UNIRIO, por exemplo, possui em sua grade a disciplina "Leitura: fundamentos teóricos e práticas transformadoras". Já a UFRJ oferece a matéria "Mediação de Leitura". A UFF tem na grade optativa a disciplina "Orientação de Leitura".

Quanto ao curso de Biblioteconomia da Santa Úrsula, não foi possível ter acesso à grade de matérias optativas. Sendo assim, não foi possível descobrir se essa faculdade oferece alguma disciplina relacionada ao assunto.

Cabe agora uma nova indagação: "Por que essas disciplinas são oferecidas como optativas e não como obrigatórias, já que a leitura e a formação de leitores constituem uma das metas das bibliotecas públicas e escolares?". Reafirmando a tese ora apresentada, a leitura é de suma importância para o desenvolvimento intelectual de qualquer cidadão, tornando-o crítico e participativo no meio em que vive.

\subsection{0 bibliotecário atuando como educador ambiental}

Partindo da questão "O bibliotecário pode atuar como educador ambiental?", na subseção anterior, discutiu-se as formas de atuação do bibliotecário no âmbito educacional. Cabe agora uma nova indagação: 
Como ele poderia trabalhar com a Educação Ambiental? De acordo com Martins e Cipolat (2006, p. 179):

A preocupação com o meio ambiente está inserida em várias áreas do conhecimento e presente no cotidiano de diferentes tipos de profissionais. Fornecer informações, com o intuito de alcançar um comportamento ecologicamente correto, gerando pensamentos críticos e atitudes conscientes com relação ao ecossistema, também são tarefas do profissional bibliotecário.

Para melhor se compreender o assunto, é necessário falar sobre os conceitos da informação ambiental e da educação ambiental. Segundo Amorim (2008, p. 1):

A informação ambiental é um tipo de informação científica e tecnológica que contribui para a preservação de ambientes naturais e dos ambientes construídos pelo homem, e é imprescindível para que a crise ambiental atual seja superada com sucesso. Porém, como não há conexão entre os mundos da informação e a realidade das populações atingidas pelas políticas públicas ambientais, faz-se necessário que os profissionais da informação procurem facilitar a difusão da informação ambiental, contribuindo para o desenvolvimento sustentável.

No entanto, a disseminação da informação ambiental ainda é muito precária. A demanda pela informação ambiental aumentou consideravelmente, pois só agora a sociedade está tomando consciência dos impactos negativos que o homem vem causando sobre a natureza.

A preocupação com a produção, o consumo sobre o meio ambiente e a escassez dos recursos naturais está resultando em novos usuários que estão recorrendo cada vez mais às fontes de informações ambientais para tentar reverter esse quadro, através de atuações diversas. De acordo com o artigo 225 da Constituição Brasileira (1988):

[...] todos têm direito ao meio ambiente ecologicamente equilibrado, bem de uso comum do povo e essencial à sadia qualidade de vida, impondo-se ao Poder Público e à coletividade o dever de defendê-lo e preservá-lo para as presentes e futuras gerações.

O desenvolvimento urbano e o descaso do homem com a natureza estão contribuindo para piorar a qualidade de vida, o que gera a necessidade de repensar o modelo de desenvolvimento do país. Esse modelo de vida é baseado na produção desenfreada e no acúmulo de capital a qualquer custo, mesmo sabendo que toda ação do homem sobre 
o meio ambiente pode causar impactos negativos e que, no futuro, esses impactos prejudicarão não só a raça humana, mas todos os seres vivos.

Neste contexto, Albagli (1995 apud TAVARES; FREIRE, 2003, p. 209) afirma que surgiu "um novo modelo de desenvolvimento econômico, caracterizado por novos meios de exploração dos recursos naturais, novos critérios de investimentos e novo paradigma técnico-científico: 0 desenvolvimento sustentável". A partir dessa afirmação, Tavares e Freire (2003, p. 209) esclarecem que "esse modelo apresenta uma constante preocupação com a melhoria da qualidade de vida das comunidades humanas, valorizando as ações por um meio ambiente saudável". Seguindo essa linha de pensamento, Vasconcelos (1998, p. 24) conclui que:

[...] o desenvolvimento sustentável tem na informação ambiental um elemento fundamental para sua viabilização, principalmente em função de alguns princípios [...] o princípio da eficácia no uso de recursos naturais (a informação é necessária para a estruturação de processos produtivos menos perdulários no consumo de energia e matérias-primas); 0 princípio da diversidade (a informação permite a identificação e a potencialização de mercados e recursos locais) e o princípio da descentralização (sendo a informação utilizada na capacitação dos atores sociais, que têm importantes papéis específicos na construção de uma sociedade sustentável social, econômica e ambientalmente).

Ainda Segundo Vasconcellos (1998, p. 43), "a opinião corrente na área ambiental é de que, no Brasil, [...] muitas bases de dados existentes carecem de atualização". A situação das instituições envolvidas com o desenvolvimento da produção da informação é tão confusa, que se torna impossível avaliar o estado da arte da produção e disseminação de informação, no país. Algumas instituições produzem informações de boa qualidade, mas, depois, entram em processos de decadência. Além disso, segundo o mesmo autor, "as informações ambientais produzidas no Brasil ainda precisam de padronização, protocolos e metodologias que assegurem a compatibilidade entre as fontes e os usuários".

[...] no Brasil houve várias iniciativas de construção de centros de dados, abrangendo diferentes áreas ambientais [...]. Alguns fatores complicadores comprometeram-lhes o sucesso, como [...] a descontinuidade associada às sucessivas substituições em cargos de direção; a deficiência de recursos humanos especializados em gerenciamento de informações, de equipamentos apropriados, as dificuldades de coleta de dados primários e restrições à sua difusão; o alto número de profissionais necessários para atuar na complexa problemática ambiental (VASCONCELOS, 1998, p. 45). 
Possibilitar o acesso à informação para melhorar as condições de vida da sociedade é fundamental (FREIRE, 2000). Nessa linha de pensamento, Hazen (1997 apud LAYRARGUES, 1998, p. 112) afirma "que o acesso à informação tem que ser entendido como integrante da democracia ambiental, pois ela é vital para instrumentar a sociedade. Se não caímos numa democracia fictícia". Neste contexto, Santos (1998, p. 166) diz que a Constituição Brasileira assegura o direito à informação:

[...] e favorece o pleno exercício da cidadania, visto que contribui significativamente com a melhoria da qualidade de vida da população, seja no sentido de prevenir/curar doenças, desenvolver hábitos saudáveis e melhorar o ambiente de vida. A internet tem sido considerada um veículo de excelência na área de comunicação social devido à multiplicidade de informações que proporciona ao indivíduo, mediante seus inúmeros sites temáticos. Estar presente nesta rede é uma necessidade hoje.

Atualmente, graças à internet, pode-se encontrar uma grande quantidade de endereços eletrônicos voltados para as questões ambientais, mas muitos disponibilizam informações incompatíveis quando comparados com outros. Por isso, é difícil saber onde se encontram fontes seguras e especializadas em informações ambientais. $O$ acesso às fontes geradoras de conhecimento nessa área muitas vezes é restrito por terem informações consideradas estratégicas. Outro fator que dificulta também é a dispersão dessas informações.

Cabe esclarecer o conceito de fontes. Segundo Souza (1998), as fontes de informações são classificadas em: fontes primárias, secundárias e terciárias. A primeira fonte contém informações originais, ou seja, dissemina a informação exatamente na forma que foi produzida por seus autores como, por exemplo, os artigos de periódicos científicos, monografias, dissertações, teses, anais de eventos, patentes e etc. Já a segunda fonte facilita o uso e o conhecimento disperso nas fontes primárias, organizando-as e encaminhando o usuário para elas. Pode-se citar como exemplo: dicionários, enciclopédias, manuais, catálogos, periódicos de indexação, resumos entre outros. As fontes terciárias de acordo com Campello e Campos (1988, p. 17):

São aquelas que têm a função de guiar o usuário da informação para as fontes primárias e secundárias. São as bibliografias, os periódicos de indexação e resumo, os catálogos coletivos, os guias de literatura, os diretórios, etc. Estas fontes se constituem nos instrumentos de trabalho do bibliotecário, que é o profissional mais indicado para produzilas e utilizá-las, a fim de aperfeiçoar o fluxo da comunicação através da literatura. 
Nesse contexto, as redes de informação são fundamentais para integração dos acervos existentes, possibilitando o acesso e a troca de informações entre os usuários e os gerenciadores das bases de dados. As redes melhoram também o controle sobre a qualidade das informações. Dentro dessa perspectiva, Vasconcelos (1998, p. 32) esclarece:

[...] os diferentes conceitos de redes existentes têm em comum as idéias de comunicação, intercâmbio de informações, interações entre entidades, associações encadeadas, ligações não hierarquizadas, malhas de ligações e fluxos de informações. A rede é um processo comunicativo que pode se desdobrar sem limites, mediante a inclusão de novos associados. A rede pressupõe instituições, indivíduos, bases de dados, normas, padrões e protocolos, equipamentos - como arquivos convencionais e computadores ligados em redes locais ou remotas - e sistemas recuperadores de informações.

Kátia de Carvalho e Reis (2007, p. 35) afirmam que a formação de redes do conhecimento amplia o espaço de trabalho do bibliotecário. Além disso, esse trabalho é de suma importância para "a disseminação da informação e do conhecimento, propondo diferentes níveis de cooperação entre as disciplinas com a finalidade de responder às questões impostas pelo desenvolvimento tecnológico proporcionando um maior diálogo entre saberes".

Cabe ao bibliotecário, além de trabalhar a formação das redes de informações ambientais, conhecê-las, tendo-as como fontes de informação para atender à demanda da sociedade e ensiná-la a usufruir dessas ferramentas. Sobre esse ponto de vista fica evidente a necessidade da atuação dos bibliotecários nesta área, ajudando da melhor forma possível a organizar, armazenar e disseminar a informação ambiental, criando estratégias, redes, projetos e outras ações, colaborando assim para conscientizar as pessoas e diminuir o impacto do ser humano no meio ambiente. Desta forma, esse profissional estará contribuindo ativamente para o desenvolvimento sustentável da região em que atua e estará colocando em prática suas habilidades e competências.

É claro que a disseminação da informação ambiental é de suma importância, mas sem a educação ambiental, ela não resultaria em mudanças de comportamentos, não geraria a consciência ambiental e muito menos sua aplicação no dia a dia. Seria como se alguém estivesse ouvindo outra pessoa falar sobre o que é certo e errado de ser fazer, sem prestar muita atenção e muito menos aprender. Nessa direção Carvalho (1998, p. 56) afirma que:

O 'fazer pelo fazer' ao invés do 'fazer consciente' não tem sustentação e acaba esmorecendo diante das primeiras dificuldades. É preciso trabalhar os valores do educando, darIhe motivos e posteriormente oferecer condições, para que este entenda seu papel diante da grave situação ambiental ao 
seu redor e possa então optar pela defesa de sua causa, assumindo de forma consciente as responsabilidades decorrentes desta escolha.

Loreiro (1998, p. 124) completa esse pensamento com a seguinte reflexão: "a simples percepção e sensibilização para o ambiente não expressa o aumento da consciência, o que faz com que se retorne o argumento sobre cidadania: a consciência para ser ecológica precisa ser crítica".

A Educação Ambiental (EA) começou a aparecer no cenário mundial na Conferência de Estocolmo na Suécia, em 1972, onde foi abordada como assunto principal. Cinco anos depois, em 1977, aconteceu a $1^{\mathrm{a}}$. Conferência Intergovernamental sobre Educação Ambiental, em Tbilissi, capital da Geórgia, Ex-URSS. E, quinze anos depois, a EA foi retomada, em 1992, na Conferência das Nações Unidas sobre Meio Ambiente e Desenvolvimento (ECO 92 e Rio 92), que aconteceu no Rio de Janeiro. De acordo com a publicação da UNESCO, as recomendações da Conferência de 92 foram ecos das de Tbilisi, das quais, uma é apresentada a seguir:

Uma das metas básicas da educação ambiental é conseguir que as pessoas e as comunidades compreendam o caráter complexo do meio ambiente natural e artificial, resultante da inter-relação de seus aspectos biológicos, físicos, sociais, econômicos e culturais e adquirir o conhecimento, os valores, as atitudes e as aptidões práticas que permitam participar, de forma responsável e eficaz, no trabalho de prever e de resolver problemas ambientais e de uma gestão qualitativamente apropriada do meio ambiente (UNESCO, 1999).

Por muito tempo, a Educação Ambiental esteve relacionada ao próprio conceito de meio ambiente, mas a prática dela atualmente, segundo Esteves et al. (1998, p. 75), "requer novas formas de abordagens, integrando vários conhecimentos, não mais reduzida a um problema natural [...] e nem restrita a uma questão social". É preciso trabalhar com a multi e a interdisciplinaridade.

Nesta direção, Tanner (1978) afirma que a EA passou a inserir o ambiente urbano em suas considerações, promovendo a articulação entre o mundo social e o mundo natural: "Com isso, transcende a perspectiva da abordagem de conteúdos meramente biologizantes, e englobam-se aspectos socioeconômicos, políticos e culturais".

Nessa perspectiva, Loreiro (1998, p. 123) nos diz:

[...] a Educação Ambiental tem por objetivo geral a formação de um cidadão consciente, capaz de agir em seu espaço de 
vida, bem como entendê-lo, em processos interativos e interdisciplinares. Transcender os limites de uma prática, ainda comum, exclusivamente informativa, de sensibilização ou de instrumentalização para a melhor gestão dos recursos naturais, pressupõe o conhecimento crítico da dinâmica societária e da constituição da cidadania contemporânea em um mundo globalizado.

A EA também deve fazer com que o homem se questione sobre sua atuação e sobre o seu papel no ambiente em que vive, percebendo que é possível aproveitar todos os benefícios que a natureza tem a oferecer, sem necessariamente destruí-la. Nessa linha de pensamento, Carvalho (1997, p. 4-5) define que a Educação Ambiental é como:

Um processo crítico transformador capaz de promover no indivíduo um questionamento mais profundo sobre a realidade ambiental onde este se encontra inserido, levando-o a assumir uma nova mentalidade ecológica, pautada no respeito mútuo para com o ambiente e os que nele convivem.

A Educação Ambiental ajuda o cidadão a perceber que também é parte integrante da natureza, como explica Morin (1998 apud CARVALHO, 1998, p. 56), reconhecendo a interligação "de todo organismo a um ecossistema qualquer, numa relação básica e fundamental de dependência/interdependência".

Neste contexto, Michel Serres (1991 apud CARVALHO, 1998, p. 56) afirma que "o homem deve abandonar a relação de parasitismo para com a natureza e passar a encará-la como algo mais do que mero pano de fundo, para desenvolvimento de sua espécie". É importante também que o homem mude seu estilo de vida como afirma Esteves et al.(1998, p. 76):

[...] conscientizar o jovem de sua importância como agente transformador do cotidiano é meta que se viabiliza através da introdução da prática da Educação Ambiental. [...] Todo e qualquer trabalho em Educação Ambiental está voltado para o futuro, pensando a relação homem/ natureza numa perspectiva de respeito pelas novas gerações. É um trabalho de longa duração, de formação de hábitos e de recuperação de valores como a solidariedade e a responsabilidade social.

Para trabalhar a Educação Ambiental é preciso conhecer a realidade social do local, com bases nas situações vivenciadas no cotidiano da população e permitir que ela participe do processo de EA. Seguindo essa linha de raciocínio, Carvalho (1998, p. 59) afirma:

É essencial que o educador ambiental procure se questionar não uma, mas quantas vezes forem necessárias, se realmente 
ele está assumindo uma postura de aprendiz, daquele que está na comunidade e/ou instituição em primeiro lugar para ouvir e aprender sobre a realidade onde pretende atuar e, não daquele que vem apenas para ensinar, pois já sabe tudo; se realmente ele está favorecendo uma atitude de diálogo com a população, ou simplesmente traz soluções prontas, desconsiderando as sugestões da comunidade em relação a um projeto já elaborado por sua equipe.

Quintas e Gualda (1995 apud LAYRARGUES, 1998, p.110) comentam que o educador ambiental deve estar capacitado "também para agir em conjunto com a sociedade civil organizada, sobretudo com os movimentos sociais, numa visão da educação ambiental como processo instituinte de novas relações entre si e dele com a natureza".

É imprescindível que os educadores de todas as áreas do conhecimento se reúnam para discutir suas expectativas, dificuldades e seus desejos, buscando no trabalho em grupo e na leitura subsídios para suas indagações. Freire (1997, p. 32) afirma que "[...] faz parte da natureza prática docente a indagação, a busca, a pesquisa. $O$ que se precisa é que, em sua formação permanente, o professor perceba e se assuma, porque professor, como pesquisador".

É necessário educar as pessoas e, como já foi visto anteriormente, o bibliotecário pode atuar com maior propriedade nesse processo. É importante questionar, portanto, como ele poderia trabalhar com a Educação Ambiental além de disseminar a informação ambiental? Esta questão será respondida na seção subsequente, ao se apresentar as experiências encontradas na literatura.

\section{Projetos de Educação Ambiental aplicados à Biblioteconomia}

Como apurado no início deste trabalho, para subsidiar o referencial teórico, foi feito um levantamento bibliográfico em algumas fontes de informação. Os termos usados na busca foram: biblioteconomia, meio ambiente e educação ambiental.

A análise da situação foi pautada, especificamente, a partir de três artigos recuperados que tratam do assunto: "Projeto: Lixo por livro" de Melo e Pessoa (1997), "Trilhas de histórias: trabalhando leitura e meio ambiente nas florestas do Rio de Janeiro" de autoria de Martins e Cardoso (2008) e " O bibliotecário como Agente Socializador na Disseminação da Informação sobre o Meio Ambiente: relato de experiência" das autoras Martins e Cipolat (2006).

O primeiro artigo trata de um projeto realizado no município de Itabira, a $100 \mathrm{~km}$ de Belo Horizonte, que tem como um de seus objetivos diminuir os efeitos negativos causados pelos resíduos sólidos ao meio ambiente e maximizar os diversos benefícios socioeconômicos, incluindo o incentivo à leitura. Este projeto consiste na coleta de latas de alumínio 
pelas entidades educacionais que vendem esses resíduos para empresas de reciclagem e com o dinheiro, segundo o artigo, compram livros literários ligados às questões ambientais.

A comunidade escolar também tem sua participação nesse processo de coleta, o que é muito importante, pois ninguém melhor do que os próprios moradores para saber dos reais problemas da comunidade e as possíveis soluções. De acordo com o resultado do relatório do projeto, no ano de 1998, os objetivos foram alcançados. Duas escolas Municipais e a Fundação Comunitária de Ensino Superior de Itabira (FUNCESI) conseguiram arrecadar com a venda de 106.480 latinhas o total de $1.460,00$ reais.

Analisando este artigo, pareceu-nos que o objetivo maior do projeto é arrecadar dinheiro para compra de livros, pois ele só visa à coleta de latas de alumínio e não citam o destino ou reciclagem de outros resíduos sólidos como o papel, plástico, vidro, etc. Também não é explicitado nada sobre a forma de atuação da biblioteca. Se ela aplica ou não a gestão ambiental em seu ambiente de trabalho e se ela promove eventos para despertar na comunidade o interesse pelas questões ambientais e pela leitura. Seria ideal se esse projeto abordasse também essas questões. Não ficou claro também o resultado do projeto em relação ao incentivo à leitura e a Educação Ambiental.

O segundo artigo trata de um projeto voluntário aplicado no Rio de Janeiro com crianças do complexo de morros do Cantagalo-PavãoPavãozinho, em Copacabana. O foco do projeto é trabalhar com crianças de 9 a 12 anos. O projeto, além de ter como objetivo principal o incentivo à leitura, visa também, através de contação/leitura de histórias, à conscientização dos alunos da Instituição Solar Meninos de Luz a terem ações ecologicamente corretas. Nele, há a intenção de unir leitura e conscientização ambiental de forma produtiva, de maneira que as duas áreas de conhecimento - Biblioteconomia e Educação ambiental - sejam trabalhadas de forma multidisciplinar.

O nome "trilhas de histórias" se deve ao fato do projeto ser realizado sempre em florestas, por acesso de trilhas. É muito importante para despertar o interesse pelo meio ambiente e colocar as crianças em contato com a natureza, para que seja possível ver, tocar, cheirar, sentir e perceber que elas também são parte integrante da natureza. É interessante ressaltar que os realizadores do projeto possuem formações diferentes: são dois bibliotecários, um músico, uma atriz, uma cineasta e uma pedagoga em formação. A ideia é que cada um contribua, com suas experiências e bagagem profissional, para o trabalho de despertar 0 sujeito-leitor e a consciência ambiental.

As histórias usadas nas contações são escolhidas e analisadas pelos realizadores do projeto, de forma que cada uma delas apresente pelo menos um personagem da floresta ou do meio ambiente. Cada história aborda um tema diferente como, por exemplo, água, árvore, desmatamento, etc. Outro fator interessante no decorrer da trilha é que, além da contação de história e a mediação de leitura, há um momento onde são discutidas questões ambientais e em seguida acontece a hora do 
lanche. Cada criança aprende a jogar o seu lixo no saco correto de coleta seletiva, separando vidro, plástico, papel, orgânico, entre outros.

Analisando este artigo, percebe-se que esse projeto é isolado, pois não trabalha em conjunto com a biblioteca. Seria interessante se a biblioteca fizesse parte para contribuir no plano de trabalho e para ajudar principalmente na formação de leitores. O projeto também poderia ajudar a tornar a biblioteca mais atraente para os alunos.

O terceiro artigo descreve um projeto realizado no município de Rio Grande, no estado do Rio Grande do Sul (RS), com crianças da $1^{\text {a. à }} 4^{a}$. séries, da Escola Barão de Cerro Largo. Este projeto tem como objetivo conscientizar os alunos, mostrando a importância de valorizar a natureza. Para isso, realizou-se uma trilha ecológica e a narração de histórias com personagens da literatura infantil, como: Chapeuzinho Vermelho, Lobo Mau, Patinho Feio, Pinóquio, Branca de Neve, entre outros.

As histórias foram criadas pelas participantes do projeto que usaram a técnica biblioteconômica de contar histórias para conduzir o aluno à realidade ambiental da natureza, incentivando-o a conservá-la.

Interessante ressaltar que esse projeto foi realizado por duas alunas de biblioteconomia da Fundação Universidade Federal do Rio Grande (FURG), no decorrer do curso. Essa faculdade foi uma das únicas encontradas que oferece uma matéria relacionada ao meio ambiente. No currículo em extinção, a matéria "Informação e Meio Ambiente" era oferecida como optativa no $8^{\circ}$ período, mas o currículo novo, que entrou em vigor em 2007, oferece a disciplina obrigatória "Princípios de Ecologia" e a optativa "Fontes de Informação - Meio Ambiente". Percebe-se que essa universidade, especificamente, tem a preocupação de relacionar a Biblioteconomia com o tema Meio Ambiente.

Analisando este projeto, nota-se que ele tem algumas características parecidas com o segundo projeto acima mencionado. Os dois procuram trabalhar a conscientização ambiental através de contação de histórias, incentivando assim a leitura também.

\section{Considerações finais}

A proposta deste trabalho tem por objetivo discutir a contribuição do bibliotecário para a Educação Ambiental, mostrando a sua importância como educador, levando o conhecimento teórico e ações práticas para as pessoas, com o intuito de que tenham ações ecologicamente corretas.

Como visto no resultado desta pesquisa, o bibliotecário deve contribuir de forma ativa para o desenvolvimento sustentável da região que atua. Deixando claro o dever de que é preciso disseminar a informação ambiental e colocar em prática suas habilidades e competências como educador, visando à conscientização ambiental da comunidade para uma melhor qualidade de vida.

Para esse fim, o bibliotecário deve se desprender das atividades tecnicistas, sem abandoná-las, visto que tais tarefas são fundamentais em qualquer biblioteca. Este profissional precisa também humanizar seu 
trabalho, visando a uma integração maior com seus usuários, melhorando assim a qualidade e eficiência de seu trabalho.

$\mathrm{Na}$ literatura consultada, fica evidente o caráter educativo do bibliotecário. No entanto, suas funções educativas não são estimuladas em sua formação, visto que os currículos das Escolas de Biblioteconomia do Rio de Janeiro, universo pesquisado, não contemplam disciplinas sobre o tema. Por isso, os currículos desses cursos deveriam ter disciplinas obrigatórias sobre educação, incluindo, também, a leitura e a formação de leitores.

Além disso, os currículos também devem oferecer matérias relacionadas ao meio ambiente, pois todo cidadão precisa ter uma base para melhorar sua qualidade de vida e poder contribuir com 0 desenvolvimento sustentável de seu país.

O curso de Biblioteconomia da FURG foi um dos únicos encontrados que oferece uma disciplina relacionada ao meio ambiente. No currículo em extinção, a matéria "Informação e Meio Ambiente" era oferecida como optativa no $8^{\circ}$ período, mas o currículo novo, vigorado em 2007, oferece a disciplina obrigatória "Princípios de Ecologia" e a optativa "Fontes de Informação - Meio Ambiente". Percebe-se que essa faculdade, especificamente, relaciona o fazer biblioteconômico com o tema Meio Ambiente. Seria de grande valia aplicar esse modelo em outras faculdades.

A Universidade Federal do Rio Grande do Sul (UFRGS) também oferece uma matéria eletiva relacionada ao meio ambiente para o curso de Biblioteconomia. A súmula da cadeira, chamada "Introdução Ecologia", é: Conceitos fundamentais da ecologia; Populações, comunidades, ecossistemas; Ciclos biogeoquímicos; Caracterização dos ecossistemas terrestres e aquáticos; O ambiente antrópico; Sistema urbano e agroecossistemas; e Poluição.

Por fim, nota-se que projetos de incentivo à leitura podem abordar muito bem as questões ambientais, relacionando a Biblioteconomia com o Meio Ambiente, ajudando os indivíduos a repensarem suas atitudes e a se tornarem pessoas mais conscientes e críticas, no meio que vivem.

\section{Referências}

ALBAGLI, S. Informação e desenvolvimento sustentável: novas questões para o século XXI. Ciência da Informação, v. 24, n. 1, 1995 apud TAVARES, C.; FREIRE, I. M. Informação ambiental no Brasil: para que e para quem. Perspectivas em Ciência da Informação, Belo Horizonte, v. 8, p. 208-215, jun./dez. 2003.

ALMEIDA JÚNIOR, O. F. Profissional da informação: entre o espírito e a produção. In: VALENTIM, M. L. P. (Org.). O profissional da informação: formação, perfil e atuação profissional. São Paulo: Polis, 2000. p. 31-51.

AMORIM, R. R. A responsabilidade social dos profissionais da informação e a preservação do meio ambiente. In: CONGRESO INTERNACIONAL DE INFORMACIÓN, 2004. Cuba. Anais... Cuba: IDICT, 2004. Disponível 
em: $<$ http://www.intempres.pco.cu/Intempres2000-

2004/Intempres2004/Sitio/Ponencias/3.pdf>. Acesso em: 21 jun. 2008.

BECKER, C. R. F.; GROSCH, M. S. A formação do leitor através das bibliotecas: o letramento e a ciência da informação como pressupostos. Revista Brasileira de Biblioteconomia e Documentação, Nova Série, São Paulo, v.4, n.1, p. 35-45, jan./jun. 2008.

BRASIL. Constituição da República Federativa do Brasil de 1988. Disponível em: $<$ http://www.planalto.gov.br/ccivil 03/constituicao/constitui\%C3\%A7ao.h $\underline{\mathrm{tm}}>$. Acesso em: 10 jan. 2010.

CAMPELLO, B. S.; CAMPOS, C. M. Fontes de informação especializada: características e utilização. Belo Horizonte: UFMG, 1988. 143 p.

CARVALHO, K.; REIS, M. B. Missão do Bibliotecário: a visão de José Ortega y Gasset. Revista Brasileira de Biblioteconomia e Documentação, Nova Série, São Paulo, v. 3, n. 2, p. 34-42, jul./dez. 2007.

CARVALHO, V. S. A ética na educação ambiental e a ética da educação ambiental: reflexões e contribuições possíveis. In: MATA, S. F. (Org.). Educação ambiental desafio do século: um apelo ético. Rio de Janeiro: Terceiro Milênio, 1998. 360 p.

CORRÊA, E. C. D. et al. Bibliotecário escolar: um educador? Revista $A C B$ Biblioteconomia, Santa Catarina, v. 7, n.1, 2002. Disponível em: $<$ http://www.acbsc.org.br/revista/index.php/racb/article/viewFile/379/459>. Acesso em: 01 abr. 2009.

DUDZIAK, E. A.; GABRIEL, M. A.; VILLELA, M. C. O. Sociedade de aprendizagem e os desafios para os profissionais da informação em sua atuação educacional. In: CONGRESSO BRASILEIRO DE BIBLIOTECONOMIA E DOCUMENTAÇÃO, 19., 2000. Porto Alegre. Anais... Porto Alegre: FEBAB, 2000. Disponível em: <http://dici.ibict.br/archive/00000717/>. Acesso em: 01 abr. 2009.

ESTABEL, L. B.; MORO, E. L. S. Capacitação de bibliotecários com limitação visual pela educação a distância em ambientes virtuais de aprendizagem. Ciência da Informação, Brasília, v. 35, n. 3, p. 209-217, 2006.

ESTEVES, A. H. R. S. et al. Ecos da razão. In: MATA, S. F. (Org.). Educação ambiental desafio do século: um apelo ético. Rio de Janeiro: Terceiro Milênio, 1998. 360 p.

FREIRE, G. H. Construindo um hipertexto com o usuário. Ciência da Informação, Brasília, v. 29, n. 3, p. 101-110, set./dez. 2000.

FREIRE, P. Pedagogia da autonomia: saberes necessários à prática educativa. São Paulo: Paz e Terra, 1997. 
HAZEN, S. Democracia ambiental. Nuestro Planeta, v. 8, n. 6, p. 31, 1997 apud LAYRARGUES, P. P. Educação para a gestão ambiental: será esta a sucessora da educação ambiental? In: MATA, S. F. (Org.). Educação ambiental desafio do século: um apelo ético. Rio de Janeiro: Terceiro Milênio, 1998. 360 p.

LOREIRO, C. F. B. Reflexões sobre os conceitos de ecocidadania e consciência ecológica. In: MATA, S. F. (Org.). Educação ambiental desafio do século: um apelo ético. Rio de Janeiro: Terceiro Milênio, 1998. 360 p.

LOURENÇO FILHO, M. O ensino e a biblioteca. Rio de Janeiro: Imprensa Nacional, 1944.

MARTINS, M. S.; CIPOLAT, S. O bibliotecário como agente socializador da disseminação da informação sobre meio ambiente: relato de experiência. Biblos, Rio Grande, n. 18, p. 179-187, 2006.

MARTINS, W.; CARDOSO, N. B. Trilhas de histórias: trabalhando leitura e meio ambiente no Horto Florestal. 2008. In: ENCONTRO REGIONAL DE ESTUDANTES DE BIBLIOTECONOMIA, 9., 2008. São Paulo. Anais... São Paulo: USP, 2008. Disponível em: < http://infocultura.info/erebd> Acesso em: 12 fev. 2009.

MARTUCCI, E. M. Sobre educação bibliotecária e perfil profissional. Palavra-Chave, São Paulo, n.3, p.2-3, out.1983.

MELO, Narcisa Helena Pessoa Lanna de; PESSOA, Júlio César Moreira. Projeto: lixo por livro. 1997 In: SEMINÁRIO BIBLIOTECA ESCOLAR: espaço de ação pedagógica, 1., 1998. Belo Horizonte. Anais... Belo Horizonte: $\quad$ EB/UFMG. $1998 . \quad$ Disponível em <http://gebe.eci.ufmg.br/downloads/118.pdf> Acesso em: 10 fev. 2009.

MILANESI, L. Biblioteca. São Paulo: Ateliê , 2002.

MORAES, R. B. O problema das bibliotecas brasileiras. Brasília: ABDF, 1983.

MORIN, E. Sociologia: a sociologia do microssocial ao macroplanetário. Portugal: Europa-América, 1998 apud CARVALHO, V. S. A ética na educação ambiental e a ética da educação ambiental: reflexões e contribuições possíveis. In: MATA, S. F. (Org.). Educação ambiental desafio do século: um apelo ético. Rio de Janeiro: Terceiro Milênio, 1998. $360 \mathrm{p}$.

PIRELA, J.; OCANDO, J. La biblioteca escolar en el contexto de la sociedad del conocimiento: algunas orientaciones para la construcción de un nuevo modelo. Infolac, v. 16, n. 2, p. 6-10, abr./jun. 2003.

QUINTAS, J.S; GUALDA, M. J. A formação do educador para atuar no processo de gestão ambiental. Brasília: IBAMA, 1995 (Série Meio Ambiente em Debate 1) apud LAYRARGUES, P. P. Educação para a gestão ambiental: será esta a sucessora da educação ambiental? In: MATA, S. F. (Org.). Educação ambiental desafio do século: um apelo ético. Rio de Janeiro: Terceiro Milênio, 1998. 360 p. 
SALGADO, D. M.; BECKER, P. O bibliotecário no olhar do público escolar. Encontros Bibli: Revista de Biblioteconomia e Ciência da Informação, Florianópolis, n. 6, p. 1-15, set., 1998.

SANTOS, E. P. Home page e a sua contribuição para a disseminação no conhecimento em educação - saúde - ambiente. In: MATA, S. F. (Org.). Educação ambiental desafio do século: um apelo ético. Rio de Janeiro: Terceiro Milênio, 1998. 360 p.

SALES, F. O ambiente escolar e a atuação bibliotecária: o olhar da educação e o olhar da biblioteconomia. Revista Eletrônica de Biblioteconomia e Ciência da Informação, Florianópolis, n. 18, 2 sem., 2004. Disponível em: $<$ http://www.periodicos.ufsc.br/index.php/eb/article/viewFile/179/1685>. Acesso em 30 mar. 2009.

SERRES, M. O contrato natural. Rio de Janeiro: Nova Fronteira, 1991 apud CARVALHO, V. S. A ética na educação ambiental e a ética da educação ambiental: reflexões e contribuições possíveis. In: MATA, S. F. (Org.). Educação ambiental desafio do século: um apelo ético. Rio de Janeiro: Terceiro Milênio, 1998. 360 p.

SILVA, E. T. De olhos abertos: reflexões sobre o desenvolvimento da leitura o Brasil. 2. ed. São Paulo: Ática, 1999. 128p.

SILVA, W. C. Miséria da biblioteca escolar. 2. ed. São Paulo: Cortez, 1999. 119p.

SOUZA, M. A. Fontes de informação em ciências exatas. São Paulo: APB, 1998.

TANNER, R. T. Educação ambiental. São Paulo: Summus/Edusp. 1978.

TAVARES, C.; FREIRE, I. M. Informação ambiental no Brasil: para que e para quem. Perspectivas em Ciência da Informação, Belo Horizonte, v. 8, p. 208-215, jun./dez. 2003.

UNESCO. Educação para um futuro sustentável: uma visão transdisciplinar para ações compartilhadas. Brasília: Ibama, 1999.

VASCONCELOS, C. R. O papel das ONGs brasileiras na produção e Disseminação de informação ambiental. 1998. Dissertação (Mestrado em Ciência da Informação) - IBICT, UFRJ, Rio de Janeiro, 1998.

WALTER, M. T. T.; BAPTISTA, S. G. A força dos estereótipos na construção da imagem profissional dos bibliotecários. Informação \& Sociedade: Estudos, João Pessoa, v.17, n. 3, p. 27-38, set./dez. 2007. Disponível em: <http://www.ies.ufpb.br/ojs2/index.php/ies/article/view/962/1583> Acesso em 10 jan. 2010. 